\title{
Following a Foraging Fish-Finder: Diel Habitat Use of Blainville's Beaked Whales Revealed by Echolocation
}

\author{
Patricia Arranz ${ }^{1 *}$, Natacha Aguilar de Soto ${ }^{1,2}$, Peter T. Madsen ${ }^{3,4}$, Alberto Brito ${ }^{1}$, Fernando Bordes ${ }^{5}$, \\ Mark P. Johnson ${ }^{4,6}$
}

1 Biodiversidad, Ecología Marina y Conservación (BIOECOMAC), Department of Animal Biology, La Laguna University, Tenerife, Spain, 2 Leigh Marine Laboratory, University of Auckland, Leigh, New Zealand, 3 Section for Zoophysiology, Department of Bioscience, Aarhus University, Aarhus, Denmark, 4 Woods Hole Oceanographic Institution, Woods Hole, Massachusetts, United States of America, $\mathbf{5}$ Instituto de Ciencias Marinas, Gran Canaria, Spain, $\mathbf{6}$ Sea Mammal Research Unit, Scottish Oceans Institute, University of St Andrews, St Andrews, Scotland

\begin{abstract}
Simultaneous high resolution sampling of predator behavior and habitat characteristics is often difficult to achieve despite its importance in understanding the foraging decisions and habitat use of predators. Here we tap into the biosonar system of Blainville's beaked whales, Mesoplodon densirostris, using sound and orientation recording tags to uncover prey-finding cues available to echolocating predators in the deep-sea. Echolocation sounds indicate where whales search and encounter prey, as well as the altitude of whales above the sea-floor and the density of organisms around them, providing a link between foraging activity and the bio-physical environment. Tagged whales $(n=9)$ hunted exclusively at depth, investing most of their search time either in the lower part of the deep scattering layer (DSL) or near the sea-floor with little diel change. At least 43\% (420/974) of recorded prey-capture attempts were performed within the benthic boundary layer despite a wide range of dive depths, and many dives included both meso- and bentho-pelagic foraging. Blainville's beaked whales only initiate searching when already deep in the descent and encounter prey suitable for capture within 2 min of the start of echolocation, suggesting that these whales are accessing prey in reliable vertical strata. Moreover, these prey resources are sufficiently dense to feed the animals in what is effectively four hours of hunting per day enabling a strategy in which long dives to exploit numerous deep-prey with low nutritional value require protracted recovery periods (average $1.5 \mathrm{~h}$ ) between dives. This apparent searching efficiency maybe aided by inhabiting steep undersea slopes with access to both the DSL and the sea-floor over small spatial scales. Aggregations of prey in these biotopes are located using biosonarderived landmarks and represent stable and abundant resources for Blainville's beaked whales in the otherwise food-limited deep-ocean.
\end{abstract}

Citation: Arranz P, de Soto NA, Madsen PT, Brito A, Bordes F, et al. (2011) Following a Foraging Fish-Finder: Diel Habitat Use of Blainville's Beaked Whales Revealed by Echolocation. PLoS ONE 6(12): e28353. doi:10.1371/journal.pone.0028353

Editor: Yan Ropert-Coudert, Institut Pluridisciplinaire Hubert Curien, France

Received July 11, 2011; Accepted November 7, 2011; Published December 7, 2011

Copyright: (c) 2011 Arranz et al. This is an open-access article distributed under the terms of the Creative Commons Attribution License, which permits unrestricted use, distribution, and reproduction in any medium, provided the original author and source are credited.

Funding: The work was funded by the Office of Naval Research and the National Ocean Partnership Program (US), by a consortium consisting of the Canary Islands Government, the Spanish Ministry of Environment and the Spanish Ministry of Defense, and by the European environmental funding LIFE-INDEMARES program for the inventory and designation of the Natura 2000 network in marine areas of the Spanish territory, headed by Fundacion Biodiversidad, with additional support from the Cabildo Insular of El Hierro. PA is currently supported by the National Research Project: Cetacean, Oceanography and Biodiversity from La Palma and El Hierro (CGL2009-13112) of the Spanish Ministry of Science and NAS by a Marie Curie fellowship from the 7th European Frame Program. MJ was supported by grants from the Strategic Environmental Research Development Program and from the National Ocean Partnership Program. PTM was supported by frame grants from the National Danish Science Foundation. The funders had no role in study design, data collection and analysis, decision to publish, or preparation of the manuscript.

Competing Interests: The authors have declared that no competing interests exist.

*E-mail: arranz@ull.es

\section{Introduction}

Foraging animals must locate food resources that are often patchy, and that change in composition and density with time and space $[1,2]$. For most terrestrial animals, the challenge of finding food is largely restricted to two spatial dimensions [3,4] where a series of biotic and abiotic landmarks may aid the location of energy resources $[5,6]$. However, for deep sea predators, prey are distributed in a 3-dimensional world of high pressure and often complete darkness that offers fewer or less obvious landmarks. Nonetheless, there are some important concentrating factors in the deep sea. Most biomass below the photic layer concentrates in two vertical strata: the deep scattering layer (DSL) [7] and the benthic boundary layer (BBL) [8]. During the day the DSL is a discrete and dense layer, consisting mostly of small (2-15 cm long) organisms, located at depths between 400 and $800 \mathrm{~m}$, while at night the more active species in the DSL disperse upwards to forage $[7,9,10]$. Species inhabiting the deeper part of the DSL tend to have reduced locomotion and perform limited or no vertical migrations [11,12] resulting in diel stability of a portion of the DSL. The BBL is considered to extend from the sea-floor to some $200 \mathrm{~m}$ altitude above it [13]. It holds most of the biomass in abyssal waters (1000-3500 m depth) and comprises typically species with low locomotory capacity [14].

The DSL and BBL constitute important foraging resources for a variety of oceanic necton including air-breathing top-predators such as marine mammals $[15,16]$. However, the abundance of prey within these layers must be balanced against the increased transport and search costs required to find and access them, especially for air breathers with limited dive times $[17,18]$. Several 
species of small marine mammals access DSL organisms when these migrate to shallow depths during the night $[15,16,19]$. This behavior saves air-breathing predators transport costs but halves their potential foraging time by restricting foraging access to nighttimes only. Other species such as elephant seals and larger toothed whales have developed the ability to perform long and deep breath-hold dives enabling them to forage in the DSL and even the BBL during day and night [20,21]. Some of these species switch between different prey types and depth layers on a dive-bydive basis $[19,22]$. However, little is known about the governing factors behind such transitions, in large part because of the difficulties involved in sampling both the behavior of deep diving predators and the composition of their bio-physical environment over similar spatial and temporal scales.

A number of studies have related predator movements to biophysical oceanographic features that influence productivity at the scales of kilometres and days to establish the extent of habitats for some species [2,23-25]. However, the temporal and spatial resolutions of such studies are insufficient to resolve specific foraging patterns as defined by local resource distributions [26]. At the other extreme, multi-sensor tags incorporating variously video, sound, and movement sampling can pin-point to the second where and when deep diving predators find prey over short time intervals [27-29], but say little about the spatial extent of the targeted prey patches.

Acoustic recording tags (such as the Dtag) [30] are well suited for studying deep-diving echolocating whales and specific acoustic signatures have been identified for when these animals are searching for, and attempting to capture, prey [31,32]. Comparing the occurrence of these signatures in sperm, pilot and beaked whales foraging in similar habitats, shows that the depths at which prey are encountered vary widely even within individual foraging dives, suggesting that these whales may be accessing a range of prey resources that change in time and space [19,33,34]. However, the difficulties involved in relating this detailed foraging behavior back to biotic parameters of the habitat are demonstrated by two recent studies. Hazen et al. [35] combined a ship-borne echosounder survey with passive acoustic detections of a deepdiving predator, Blainville's beaked whale (Mesoplodon densirostris), to show that this species was more abundant in areas where the backscatter strength of the DSL was large. However, the uniform $400-600 \mathrm{~m}$ depth of the DSL in the study site is at odds with the 700-1100 m foraging depths of the same species tagged with acoustic tags in the same area and at the same general time [36]. This apparent contradiction suggests either that the prey sampling methods are too coarse or that there is a more complex ecological relationship between beaked whales and the DSL, requiring simultaneous high resolution sampling of prey abundance and predator behavior. This scale problem is especially acute in areas with high spatial variability such as the steep bathymetric zones around shelf edges, sea-mounts or oceanic islands often favored by deep-diving predators [24,37].

Here we use a novel source of information providing simultaneous sampling of a predator and its environment to examine the foraging ecology of Blainville's beaked whales. Acoustic tags on this species record both the echolocation sounds produced by tagged whales, including distinctive buzzes indicating prey capture attempts, but also the echoes from the sea surface, sea-floor and organisms in the water column, insonified by these sounds [31,32]. These data create a unique opportunity to uncover some of the instantaneous cues available to a predator in the deep sea for finding its prey, providing a direct connection between the whale's bio-physical environment, as it encounters it, and its foraging efforts. Using tag recordings from nine Blainville's beaked whales diving in steep bathymetry near an oceanic island, we show that foraging is concentrated around the deep scattering and benthic layers and that whales often switch between mesoand bentho-pelagic foraging within the same dive in a way that is not always evident from the dive profile. We explore the ecological implications of this foraging behavior for prey and habitat selection by this air-breathing top-predator in the deep ocean.

\section{Methods}

\section{Ethics statement}

Animal tagging was approved by the Woods Hole Oceanographic Institutional Animal Care and Use Committee (proposal 7175) and conducted under a permit issued by the Canary Islands Government to N. Aguilar Soto from La Laguna University (Permits \# 21/2004, 41/2005, 132/2006, 487/2007, 269/2008, 261/2009).

\section{Data collection}

Field work was performed from 2003 to 2010 off El Hierro, in the Canary Islands, where there is a year-round population of Blainville's beaked whales close to shore. Suction-cup attached digital recorders (Dtag) [30] were used to collect acoustic and movement data. The tags sampled depth and orientation of the whales at $50 \mathrm{~Hz}$ and these sensor streams were decimated to $5 \mathrm{~Hz}$ for analysis. Acoustic data were sampled from one or two hydrophones at $96 \mathrm{kHz}$ (in 2003) and $192 \mathrm{kHz}$ (in 2004 and onwards) [38]. Data were gathered from 9 individual Blainville's beaked whales in 14 tag deployments. Whales were identified with the aid of photos of their individually-distinctive scar patterns but the difficulty in recognizing individuals at the moment of tagging resulted in four animals being tagged more than once in different years (Table 1). Impact on the whales due to re-tagging is expected to be small given the long inter-tagging intervals $(>1$ year) and the short-term superficial attachment of the Dtag. To further reduce the potential impact of tagging, only adult and sub-adult whales not accompanied by calves were tagged and a maximum of three tagging attempts (approaches of the boat within $100 \mathrm{~m}$ of the whales) were performed on a group of whales in any given day.

\section{Dive cycle}

Tag acoustic recordings were evaluated by examining consecutive spectrograms (512 sample Hann window, 1024 bin FFT) of $20 \mathrm{~s}$ of data to locate buzzes, and the beginning and end of the vocal phase in each dive. Buzzes are considered indicative of prey capture attempts [31,39] while the beginning and end of vocalizations (clicks) in a dive are taken as indicating the duration of prey search by echolocation [33,34]. A supervised click detector (a band-pass energy detector with a user-selected threshold) was used to identify individual clicks for later echo analysis. Based on the sound events and dive profiles, we divided the dive cycle into three phases: (i) transport: the time elapsed from leaving the surface to the start of echolocation clicking (SOC) plus the time elapsed from the end of clicking (EOG) to re-gaining the surface; (ii) search: time elapsed from SOC to EOC in a foraging dive, i.e., the time spent echolocating; (iii) inter foraging dive interval (IFDI): time spent at the surface or in silent shallow dives between deep foraging dives. Only full dive cycles (i.e., a foraging dive+complete IFDI), and therefore only those tag records with at least one full dive cycle, were examined for time allocation in these dive phases.

\section{Foraging activity}

To test for circadian changes in foraging behavior, we performed a day/night comparison of: i) the depth of the start 
Table 1. Dive and foraging statistics.

\begin{tabular}{lllllllll}
\hline Whale & Date & $\begin{array}{l}\text { Tag } \\
\text { duration }\end{array}$ & $\begin{array}{l}\text { FD/FD } \\
\text { bot }\end{array}$ & $\begin{array}{l}\text { FD duration } \\
\text { (mean, range) }\end{array}$ & $\begin{array}{l}\text { FD max. depth } \\
\text { (mean, range) }\end{array}$ & $\begin{array}{l}\text { SOC depth } \\
\text { (mean, range) }\end{array}$ & $\begin{array}{l}\text { Search } \\
\text { (mean, range) }\end{array}$ & $\begin{array}{l}\text { \# Buzz } \\
\text { (mean-range) }\end{array}$ \\
\hline MdH1 & $2008-05-16$ & 18.4 & $7 / 7$ & $48(33-65)$ & $911(491-1330)$ & $448(179-873)$ & $28(21-38)$ & $35(18-49)$ \\
& $2005-10-21$ & 4.1 & $3 / 2$ & $50(48-51)$ & $671(597-790)$ & $475(457-492)$ & $22(22-22)$ & $24(20-28)$ \\
& $2003-10-11$ & 12.5 & $5 / 3$ & $51(40-57)$ & $616(616-616)$ & $414(183-566)$ & $26(18-31)$ & $26(12-44)$ \\
\hline MdH15 & $2003-10-25$ & 2.6 & $2 / 2$ & $47(45-48)$ & $774(732-815)$ & $426(416-434)$ & $25(23-27)$ & $23(20-27)$ \\
\hline MdH22 & $2008-10-15$ & 18.0 & $7 / 2$ & $44(23-57)$ & $710(472-963)$ & $340(193-560)$ & $23(9-32)$ & $21(4-34)$ \\
\hline & $2005-10-21$ & 2.8 & $1 / 0$ & $47(47-47)$ & $616(616-616)$ & $520(520-520)$ & $21(21-21)$ & $18(18-18)$ \\
\hline MdH6 & $2004-10-13$ & 9.5 & $4 / 3$ & $44(34-55)$ & $1003(715-1311)$ & $473(448-499)$ & $28(23-33)$ & $32(25-37)$ \\
\hline MdH43 & $2008-05-15$ & 2.0 & $2 / 2$ & $48(44-52)$ & $781(779-784)$ & $389(326-454)$ & $24(20-27)$ & $23(19-27)$ \\
MdH74 & $2005-10-04$ & 6.9 & $3 / 3$ & $57(51-62)$ & $914(869-953)$ & $518(513-524)$ & $25(22-29)$ & $29(23-37)$ \\
MdHC1 & $2005-10-12$ & 8.6 & $4 / 4$ & $45(39-52)$ & $833(674-1011)$ & $505(482-540)$ & $25(25-26)$ & $43(37-53)$ \\
MdHX33 & $2008-05-21$ & 1.6 & $1 / 1$ & $47(47-47)$ & $807(807-807)$ & $419(419-419)$ & $20(20-20)$ & $11(11-11)$ \\
MdH86 & $2010-05-26$ & 2.9 & $1 / 1$ & $48(48-48)$ & $925(925-925)$ & $503(503-503)$ & $22(22-22)$ & $34(34-34)$ \\
\hline
\end{tabular}

Summary of statistics for 50 foraging dives from 14 tag deployments on 9 Blainville's beaked whales off El Hierro. Values in the last 5 columns are means over each tag deployment with the range given in parentheses. Whale: database code of the tagged whale (www.cetabase.info); Date: year, month and day of tagging; Tag duration: tag recording duration in hours. FD: number of complete foraging dives; FD bot: number of complete foraging dives containing echoes from the sea-floor; FD duration: length of foraging dives in minutes. SOC depth: depth in meters of start of regular clicking; Search: time elapsed between start and end of clicking in each dive; \# Buzz: number of buzzes emitted per dive.

doi:10.1371/journal.pone.0028353.t001

of clicking and the first buzz in dives; ii) the number of buzzes per dive; iii) the maximum buzz depth in each dive, and (iv) the proportion of time spent in search and transport for all individuals. A dive was considered to be performed during the day or night if the SOC occurred before or after local sunset. Comparisons were made with nested ANOVA using day-night as the main grouping factor and individual as the sub-grouping factor. The relative importance of the main and sub-grouping factors was estimated using partial-eta-squared coefficients $\left(\mathrm{p \eta}^{2}\right)$ [40].

To test for a circadian change in the depth range over which foraging took place, depth distributions in $50 \mathrm{~m}$ depth bins were computed for the search time, buzz count, and buzz rate (i.e., the number of buzzes in each depth bin divided by the time spent in that depth bin) in 4 tag deployments on 3 individuals that spanned day and night. These distributions indicate, respectively, the depths at which whales search for and encounter prey, and the rate at which they find prey as a function of depth. Individual depth distributions in day and night dives were compared using a Kolmogorov-Smirnov test.

\section{Echoes from the sea-floor and organisms}

All tags recorded echoes from both the sea-floor and from organisms near the tagged whale ensonified by clicks from the whale. Echoes were identified using echograms generated as a stack plot of the envelope of high-pass filtered sound segments following each out-going click (sensu [31]). The cut-off frequency of the filter was set to the lower $-10 \mathrm{~dB}$ frequency of Blainville's beaked whale frequency-modulated (FM) clicks $(27 \mathrm{kHz})$ [38]. Sound segments of $1 \mathrm{~s}$ duration were used to detect sea-floor echoes at distances of up to $750 \mathrm{~m}$ from the whale. Echoes from the sea-floor appeared in echograms as light-shaded areas (Fig. 1C) with an abrupt onset time corresponding to the two way travel time (TWT) from the whale to the closest sea-floor surface. The TWT was estimated using a supervised edge detector (resolution $<500 \mu \mathrm{s}$ ) and converted to the altitude of the whale above the sea-floor (whale-altitude here on) by multiplying the TWT by one half of the path-integrated sound speed. The TWT to range conversion was iterated several times from a fixed starting sound speed estimate $(1500 \mathrm{~m} / \mathrm{s})$ to resolve path length and pathintegrated sound speed in tandem. The sound speed profile required by this algorithm was measured with a CTD cast to a depth of $1300 \mathrm{~m}$ in the same area and extrapolated to deeper depths using a constant temperature and salinity assumption. The sea-floor depth was estimated by adding the whale-altitude to the depth of the whale (whale-depth here on) as recorded by the tag pressure sensor. The low source level of buzz clicks (some $20 \mathrm{~dB}$ lower than FM clicks) [32] precluded the detection of sea-floor echoes during buzzes. Thus, the whale-altitude during buzzes was estimated using sea-floor depths acquired up to $60 \mathrm{~s}$ before or after each buzz, corrected by the whale-depth during the buzz. The mean change in sea-floor depth recorded over $60 \mathrm{~s}$ intervals outside of buzzes during the vocal search phase was $9 \mathrm{~m}$, indicating the likely order of error incurred by this approximation.

Echoes from organisms in the water column were recorded at ranges of more than $20 \mathrm{~m}$ from the whale and varied in density of occurrence from a few discrete echoes to nearly continuous backscatter (Fig. 1B,D). Manual identification of sequences of echoes from distinct organisms has been attempted previously $[32,41]$ but this is unreliable when echo density is high. To quantify the abundance of echoes as a function of depth over a range of echo densities we used an automatic echo counting method. The RMS sound pressure level was computed for ten $1 \mathrm{~ms}$ long samples of filtered sound (6-pole Butterworth band-pass filter with $25-50 \mathrm{kHz}$ cut-off frequencies) taken from the 5 th to the 15 th $\mathrm{ms}$ after each click produced by the whales (corresponding to echoic targets 3.75 to 11.25 meters from the whale). The RMS level in each of the 10 sound samples was compared against the RMS level of a $10 \mathrm{~ms}$ sound sample taken just before the same click, with the same filter settings, representing a measure of the instantaneous ambient sound level at the tag. This comparison provided an estimate of 

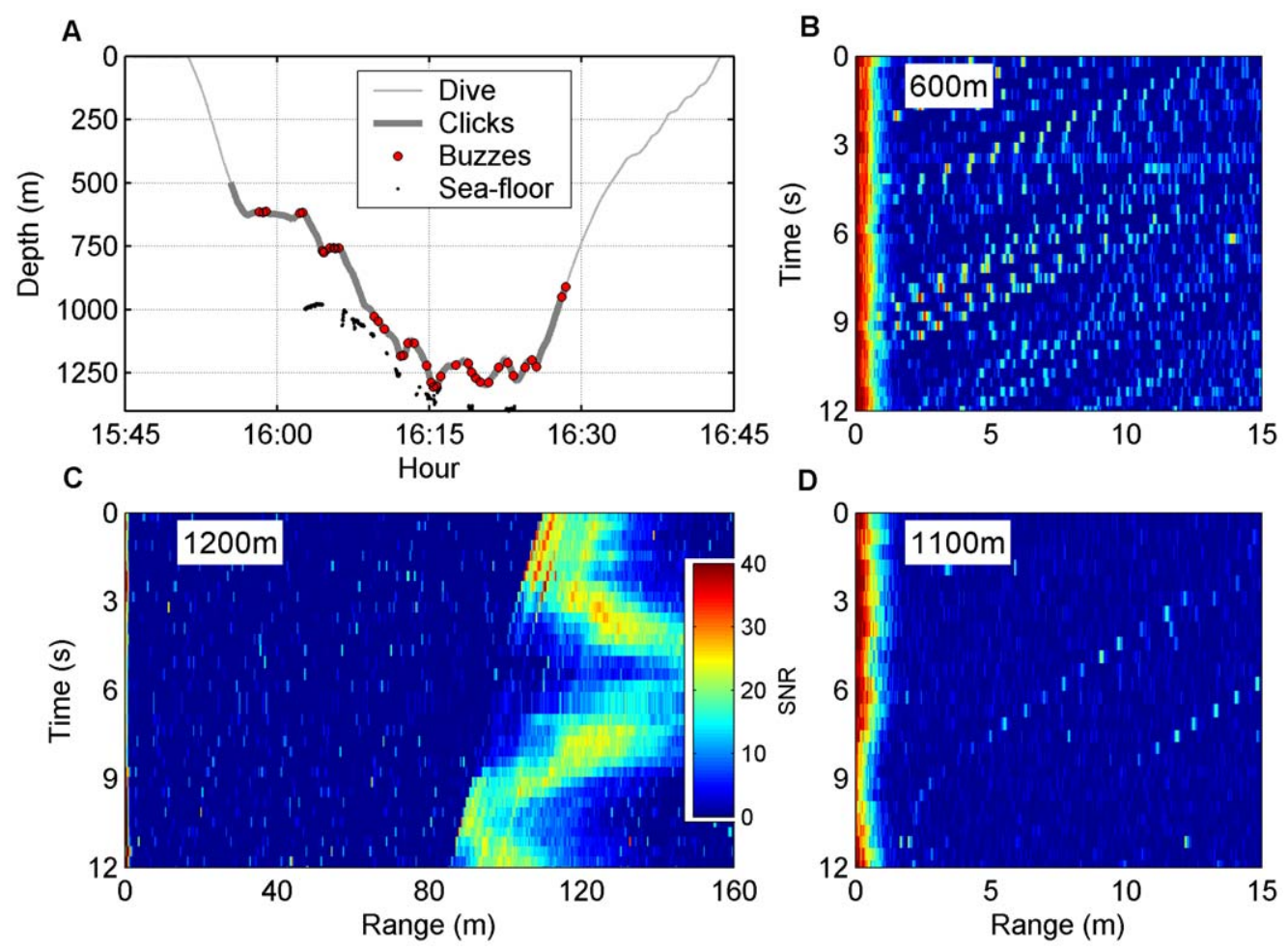

Figure 1. Foraging dive profile and echograms showing sea-floor and organisms ensonified by the whale. (A) Dive profile of a female Blainville's beaked whale ( $\mathrm{MdH} 22$ tagged on 10/03/04) showing the vocal phase of the dive (thick grey line), the location of the buzzes (black circles) and the seafloor (red dots). (B, D) Echograms with a range span of $15 \mathrm{~m}$ indicating the distance from the whale to echoic organisms on consecutive clicks. Echoes appear as dots coloured by the signal-to-noise ratio of the echo. In these examples, the echo counts are 198 echoes/60 clicks (B) and 6 echoes/35 clicks (D). The red thick lines on the left of the plots are the clicks emitted by the whale. (C) Echogram with a range span of $150 \mathrm{~m}$ showing reverberant reflections off the sea-floor which was 90-120 m below the whale.

doi:10.1371/journal.pone.0028353.g001

the signal-to-noise ratio (SNR) in each post-click sound sample and samples with $\mathrm{SNR} \geq 6 \mathrm{~dB}$ were considered to include an echo. The number of these samples containing echoes was averaged over all clicks produced by all whales in $50 \mathrm{~m}$ depth bins to produce a nominal measure of echoes per click in each depth bin. Data from two tags (summing 12 dives) were excluded from this analysis because echoes in these tags were masked by high flow noise, possibly due to a caudal tag placement.

To validate the automatic echo counting method, results were compared to manual echo counts obtained by inspection of echograms on a sub-set of the data. Results from the two methods were correlated with a slope of 0.6 (Spearman correlation $\rho=0.80$, $\mathrm{n}=953$ clicks, 422 echoes identified manually and 296 echoes gathered with the automatic tool). The automatic method gave consistently lower counts than the manual method due to the relatively conservative detection threshold and averaging window $(6 \mathrm{~dB}$ and $1 \mathrm{~ms}$, respectively) in the former. The number of echoes detected from a series of clicks is dependent on the number and target strength of organisms ensonified, and also the number of consecutive clicks that each organism remains in the echolocation beam. This last factor depends on the types of organisms ensonified and also on the whale's movements which may vary throughout a dive. As a result, the echo count described here should be considered as a relative measure of organismal density rather than a direct estimate of the number of organisms that the whale encounters.

\section{Oceanographic and hydroacoustic data}

Sound speed and oxygen concentration depth profiles were gathered with a conductivity, temperature and depth recorder
(CTD, RBR XR-620) lowered at a rate of $60 \mathrm{~m} / \mathrm{min}$ to $1000 \mathrm{~m}$ depth. A hydroacoustic survey was performed in June 2009 using an uncalibrated SIMRAD EK-60 splitbeam echosounder operating at $38 \mathrm{kHz}$ with a beamwidth of $7.2^{\circ}$. Data were collected using $2 \mathrm{~kW}$ pulses of $1024 \mu \mathrm{s}$ duration and sampling interval $0.196 \mathrm{~m}$. Background noise (approx. $-129 \mathrm{~dB} \mathrm{re} \mathrm{m}^{-1}$ ) was automatically estimated using the minimum sample power in bins of 20 pulses horizontal and $10 \mathrm{~m}$ range following De Robertis \& Higginbottom [42]. The mean volume-backscatter strength $\left(\mathrm{dB} \mathrm{re} \mathrm{m}^{-1}\right)$, a logarithmic measure of volume backscattering [43], was estimated from 0 to $1000 \mathrm{~m}$ depth and visualized with the aid of echograms after noise correction. Hydroacoustic transects, each covering $3680 \mathrm{~m}(2 \mathrm{~nm})$, were performed day and night between the 1000$2000 \mathrm{~m}$ isobaths some $3 \mathrm{~km}$ from the shore. Both CTD and hydroacoustic data were gathered in the core area of distribution of Blainville's beaked whales off El Hierro.

\section{Results}

A total of 111.4 hours of combined acoustic and movement data were gathered from 14 tag deployments, including 50 complete foraging dives and 33 dive cycles (Table 1). Tagged Blainville's beaked whales performed long and deep foraging dives with a mean duration of $48 \mathrm{~min}$ (23-65 min) and a mean maximum dive depth of $833 \mathrm{~m}(472-1330 \mathrm{~m}$ ) (values are given as the mean with the range in parentheses). Whales started echolocating at a mean depth of $425 \mathrm{~m} \mathrm{(169-873} \mathrm{m)} \mathrm{after} \mathrm{a} \mathrm{silent} \mathrm{descent}$ lasting on average $4 \mathrm{~min}(1-11 \mathrm{~min})$. Echolocation stopped at a mean depth of $712 \mathrm{~m}(273-1027 \mathrm{~m})$ and was followed by a silent 
ascent lasting on average $19 \mathrm{~min}$ (9-35 $\mathrm{min})$. The sum of the silent descent and ascent phases resulted in a mean transport phase duration of $23 \mathrm{~min}(12-33 \mathrm{~min})$. The search phase lasted on average $24 \mathrm{~min}$ (9-38 $\mathrm{min})$ (Fig. 2), with whales producing an average of 27 buzzes per dive (4-53 buzzes).

Between consecutive deep dives, whales spent a mean of $92 \mathrm{~min}$ (4-188 min) performing a series of shallow and silent dives not related to foraging [34]. Thus, tagged Blainville's beaked whales devoted $18 \%$ of their time to transport within foraging dives, $18 \%$ in search and acquisition of prey, and $64 \%$ to non-vocal shallow diving between deep dives (Fig. 2). Within the searching phase, whales spent on average only $2 \mathrm{~min}$ (0.6-3.1 min) echolocating before making the first prey capture attempt in each dive.

\section{Day/night foraging preferences}

Diel differences were tested in 11 tag deployments on 9 individuals that contained at least two complete dives. These recordings comprise in total 73 hours and 46 dives, (15 hours and 12 dives of which occurred at night-time). Tagged whales started clicking (i.e., searching for prey) and emitting buzzes (attempting to capture prey) at significantly shallower depths at night than during the day (Figs. 3A, 4E and 5A). The mean SOC depth was $479 \mathrm{~m} \mathrm{(276-589)}$ and $258 \mathrm{~m} \mathrm{(168-873)}$ for day and night, respectively (nested ANOVA, $\mathrm{p}=0.001, \mathrm{pc}^{2}=0.55$ for diel factors and $\mathrm{p}=0.42, \mathrm{pc}^{2}=0.37$ for individual factors) and mean depth of the first buzz was $755 \mathrm{~m}$ (563-1027) and $572 \mathrm{~m}$ (273-904) for day and night, respectively (nested ANOVA, $\mathrm{p}=0.005, \mathrm{pc}^{2}=0.57$ for diel factors and $\mathrm{p}=0.08, \mathrm{pc}^{2}=0.50$ for individual factors). Because both the depth at which whales started clicking and the depth of the first buzz changed by about the same amount from day to night, there was little diel variation in the time spent searching for prey before the first buzz, $2.1 \mathrm{~min}(0.04-4.5)$ during the day and $1.9 \mathrm{~min}(0.3-4.9)$ at night, (Ranksum, $\mathrm{p}=0.53, \mathrm{n}=46$ dives).

Although whales started to forage shallower at night, there was no detectable change in the depth distribution of search time or buzz rate from day to night in the 3 individuals that could be tested. These whales performed both day and night-time dives allowing for the comparison of these parameters in a tag-by-tag basis (15 and 12 dives in day and night-time respectively). The depth distribution of buzzes only showed significant circadian variations in one of the three individuals (Kolmogorov-Smirnov, $\mathrm{n}=15$ depth bins of $50 \mathrm{~m}, \mathrm{p}=0.01$ for that deployment). There was no evidence for circadian changes either in the maximum depth of buzzes, the number of buzzes per dive, or the time allocated to transport and foraging within dives. In summary, whales searched and found prey over a greater depth range, starting at shallower depths at night-time than during the day, but they made use of deep foraging resources both day and night.

\section{Altitude of foraging}

Sea-floor echoes were found in 13 of the 14 tag deployments (the only tag without sea-floor echoes recorded a single foraging dive) and in 40 of the 50 foraging dives (Table 1, Fig. 3A). Over all tags, the sea-floor depth, as calculated from echoes, varied between 414 and $1425 \mathrm{~m}$ with a median of $885 \mathrm{~m}$. Whalealtitude above the sea-floor varied from 535 to as little as $5 \mathrm{~m}$ (i.e., about a body length) with a median of $127 \mathrm{~m}$. Using a $60 \mathrm{~s}$ extrapolation interval, whale-altitude and bottom depth could be estimated for $64 \%$ of the echolocation time. Sea-floor echoes will become weaker and harder to detect as the whale-altitude increases and so some intervals without echoes may occur in water that is too deep to register echoes. However, sea-floor echoes also should be detected most readily when whales are pointing downwards and so more likely to ensonify the sea-floor with their narrow forward-directed sonar beam. That orientation is a key determinant of whether a bottom echo is detected was confirmed by comparing the distribution of pitch angles of whales when echoes were recorded against the overall pitch angle distribution of whales while clicking (Wilcoxon rank-sum, $\mathrm{p} \ll 0.001$ for equal median pitch angles, $n=11228$ clicks with bottom echoes compared with 55155 clicks with and without echoes). Some $70 \%$ of clicks with sea-floor echoes were obtained at pitch angles below $0^{\circ}$ (a downwards pointing whale has a negative pitch angle), while the overall pitch distribution during foraging was roughly symmetric around $0^{\circ}$.

When the sea-floor depth could be tracked reliably, whales often seemed to follow a downward sloping sea-floor while they foraged (Fig. 3). To test if this was a stereotyped behavior, we estimated the slope of the sea-floor along the course taken by the whales, in terms of meters of depth change per minute (converting this to a more conventional slope in meters per meter requires the whale's speed which was not available). Pooling all dives with sea-floor echoes and removing the mean sea-floor depth in each dive, a mean sea-floor slope of $-9 \mathrm{~m} / \mathrm{min}$ was found (Spearman correlation between time and bottom depth, $\rho=0.68, \mathrm{p} \ll 0.001$, 40 dives with at least 5 depths/dive, $\mathrm{n}=6142$ sea-floor depths). Regressing individual dives, all 40 dives with sea-floor echoes had a negative bottom slope, confirming that tagged whales routinely swam down-slope when foraging.

Discontinuous detection of sea-floor echoes resulted in whalealtitude estimates for only 535 of 974 buzzes (i.e., 55\%), spanning 40 of 50 dives. Buzzes with measurable altitude were performed at

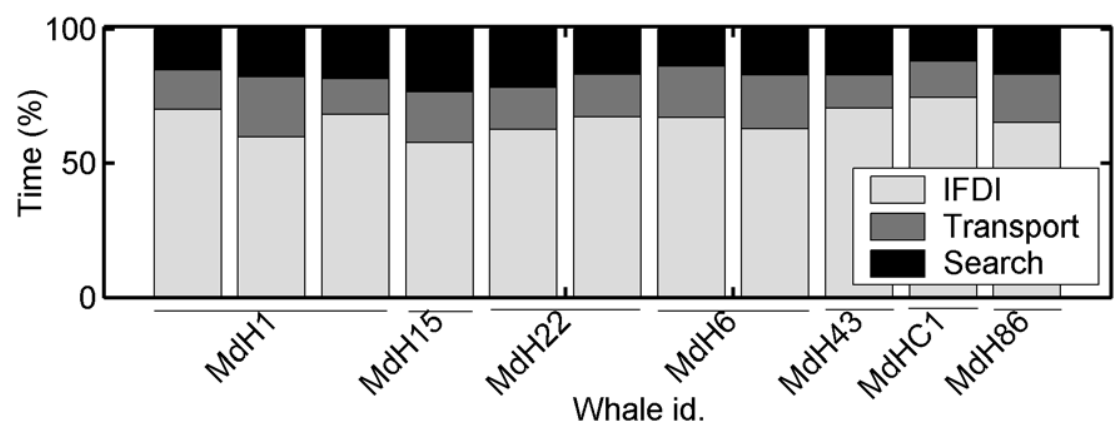

Figure 2. Time budget. Time budget of seven whales in 11 tag deployments with at least two complete foraging dives. The bars represent the proportion of time invested in: inter foraging dive intervals (IFDI, light grey), silent transport to and from foraging depths within deep foraging dives (dark grey) and searching (i.e., echolocating) for prey (black).

doi:10.1371/journal.pone.0028353.g002 
A
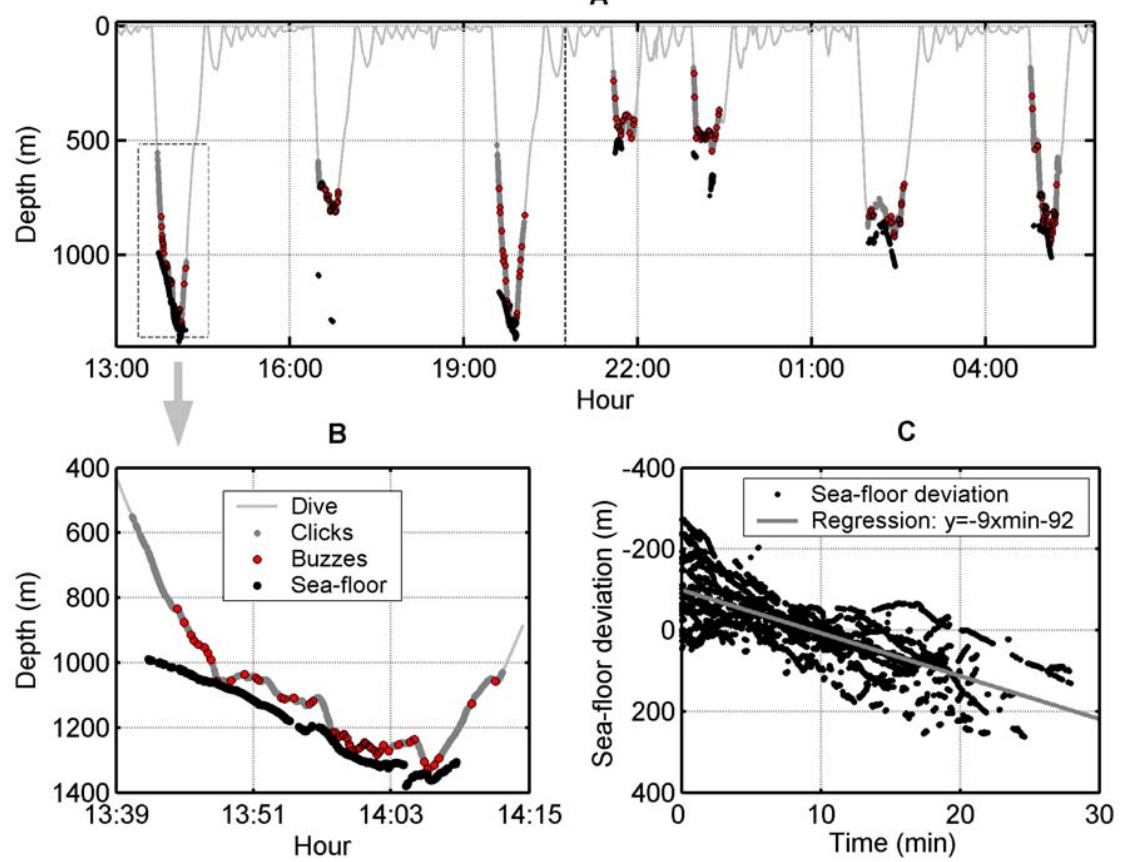

Figure 3. Whale foraging activity in relation to the sea-floor. (A) Dive profile of a male Blainville's beaked whale (MdH1 tagged on 16/05/08). Thick grey lines indicate the vocal phase of the dives (echolocation) and grey circles represent foraging attempts (buzzes). Black dots show the location of the sea-floor and the vertical dashed line at 20:45 h indicates sunset. The whale approached the sea-floor in most dives despite diving to a wide range of depths. (B) Detailed view of part of the first dive when the whale follows the sea-floor contour to forage. (C) Deviation of the sea-floor depth, in the directions taken by tagged whales, as a function of dive time. The sea-floor deviation is the instantaneous sea-floor depth minus the mean sea-floor depth over each dive. The negative slope of the regression line indicates a tendency for whales to forage down-slope. doi:10.1371/journal.pone.0028353.g003
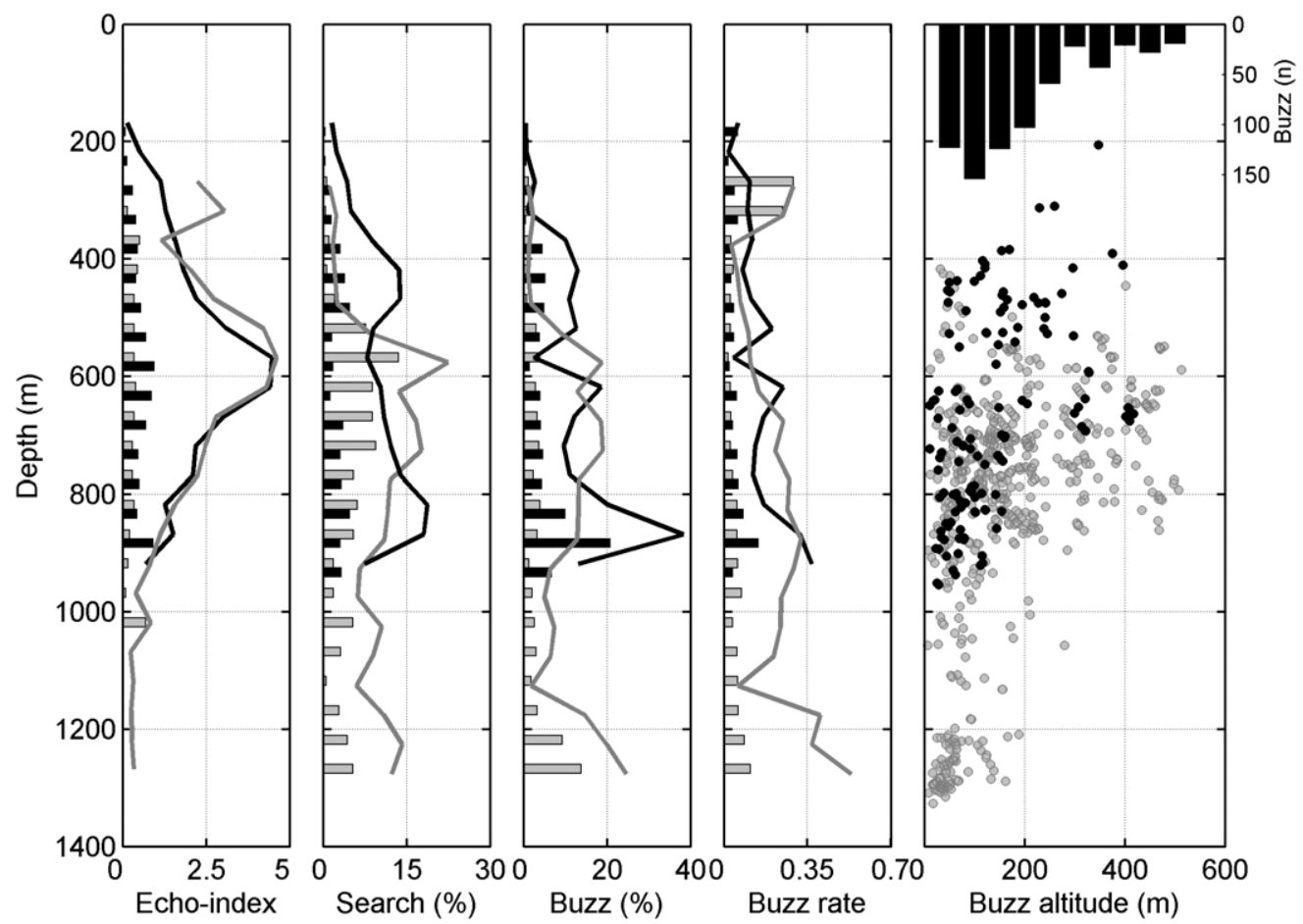

Figure 4. Day and night depth profiles of echo and foraging parameters. (A) Echo-index, indicative of the relative density of echoic organisms insonified, (B) proportion of time spent echolocating per depth bin, (C) proportion of buzzes produced per depth bin, (D) buzzes per minute spent in each depth bin. Lines and bars correspond to the mean and standard error, respectively, of the above parameters for day (grey) and night (black) dives. These plots represent pooled data for all dives from all tag deployments in $50 \mathrm{~m}$ depth bins except the echo-index, which was not possible to quantify for two tags (6 dives) due to high flow-noise levels. (E) whale depth and altitude above the sea-floor for each buzz recorded within $60 \mathrm{~s}$ of a sea-floor echo (black and grey dots for night and day time buzzes, respectively) and histogram of whale-altitude in $50 \mathrm{~m}$ bins for those buzzes (top black bars).

doi:10.1371/journal.pone.0028353.g004 
A

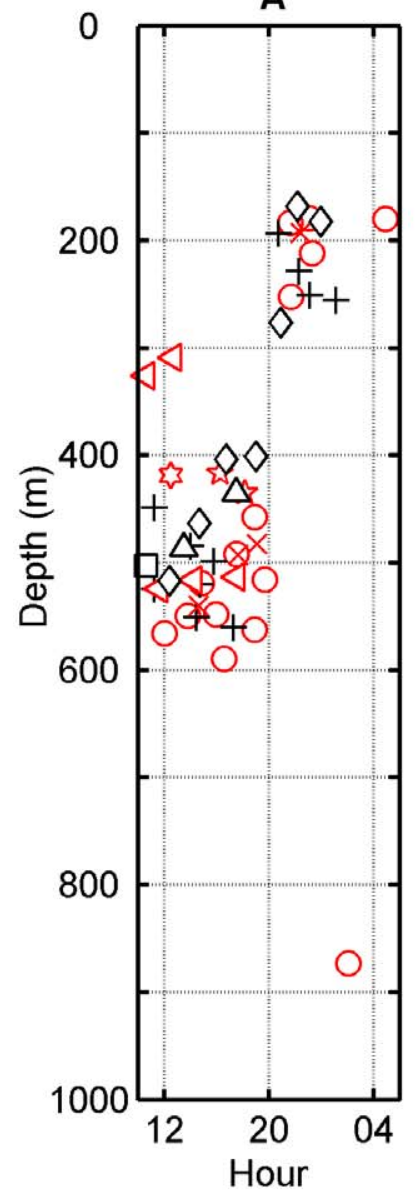

B

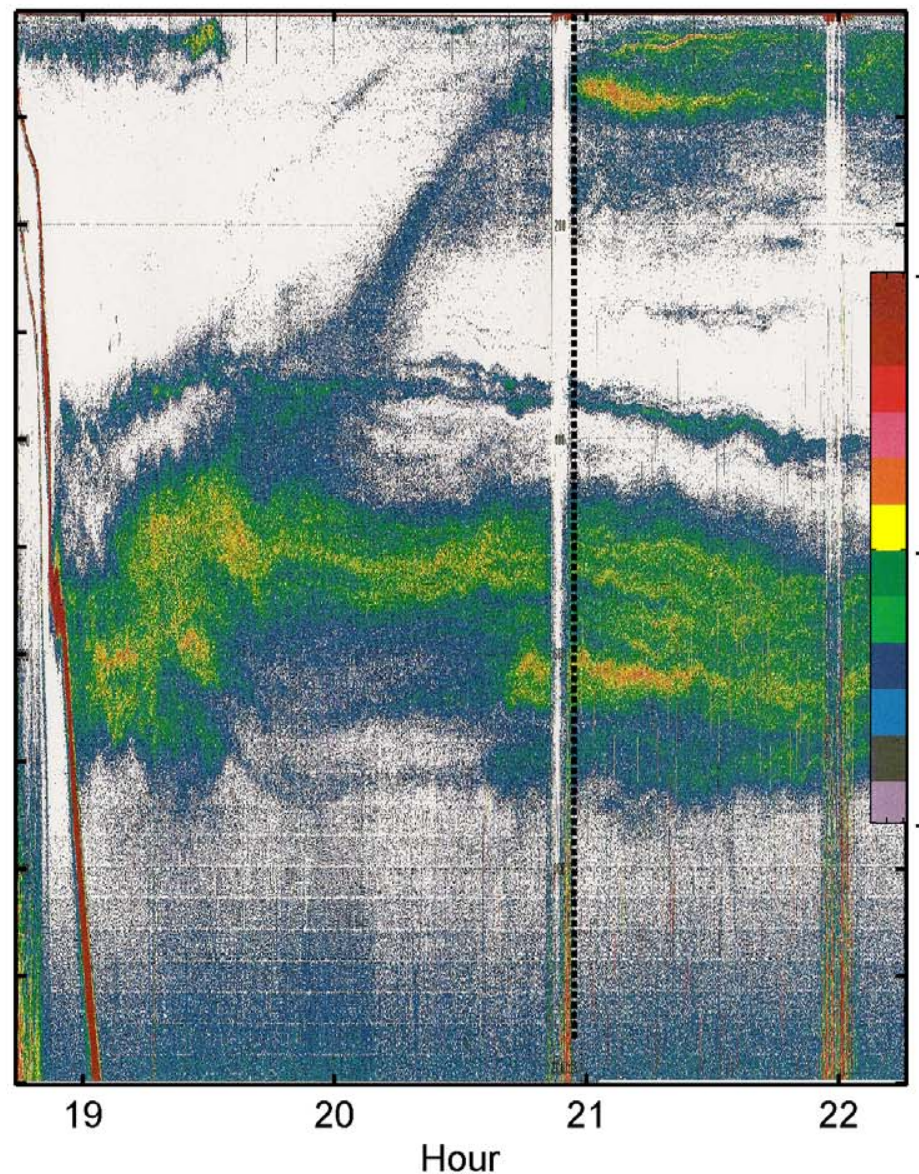

C

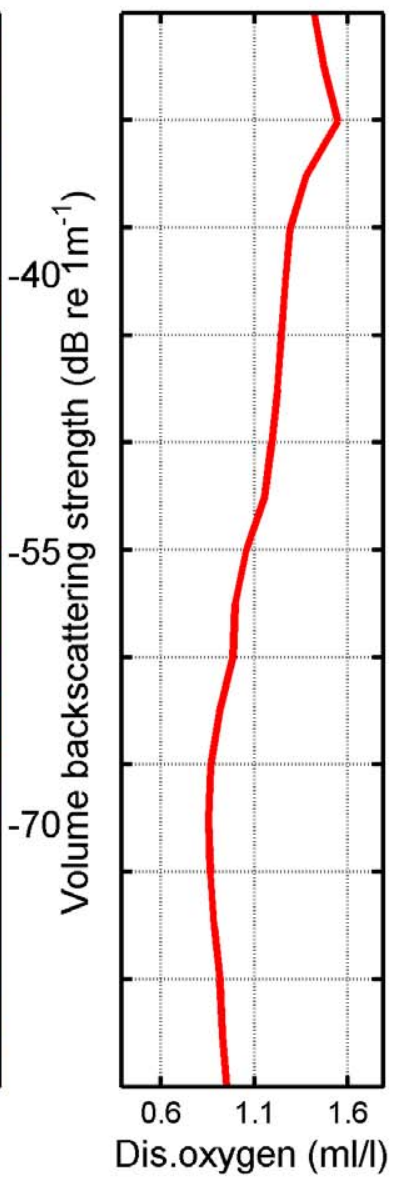

Figure 5. Whale start of clicking in relation to biological and physical parameters of the study area. (A) Depth at which tagged whales ( $n=9$ individuals, identified with different symbols) start echolocating in 50 foraging dives performed at different hours of the day. (B) Echosounder profile showing the depth distribution of the biomass in the study area off El Hierro during the day-night transition. The colours indicate echo intensity in $\mathrm{dB}$ re $1 \mathrm{~m}^{-1}$. The vertical dashed line indicates the time of sunset and the red areas correspond to echoes from the sea-floor. The white bands result from outages in echo reception due to air bubbles produced by manoeuvres of the boat. The circadian vertical migration of the deep scattering layer is evident. (C) Profile of the dissolved oxygen concentration $(\mathrm{ml} / \mathrm{l})$ in the same waters.

doi:10.1371/journal.pone.0028353.g005

a median altitude above the sea-floor of $139 \mathrm{~m}(5-507 \mathrm{~m})$ and mean depth of $815 \mathrm{~m}$ (309-1326 m). Two general trends are evident in the whale altitude data (Fig. 4E): at whale-depths of up to $900 \mathrm{~m}$, encompassing a majority of the buzzes, whales fed at a range of altitudes above the sea-floor but mostly at altitudes $<250 \mathrm{~m}$. At deeper foraging depths, feeding took place almost exclusively within $200 \mathrm{~m}$ of the sea-floor. There is certainly little evidence in Fig. 4E for pelagic foraging deeper than about $900 \mathrm{~m}$. However, pelagic foraging may occur in shallower parts of dives and involve some of the buzzes for which sea-floor echoes were not obtained. Buzzes without sea-floor echoes tended to be shallower (mean of $696 \mathrm{~m}$, range 359-1288 m) than buzzes with echoes, but were not necessarily made with an upward pitch angle (mean pitch angle in the surrounding $60 \mathrm{~s}$ of each buzz was $1^{\circ}$ ), suggesting that the sea-floor was out of detection range in many of these buzzes.

Following the traditional definition of the benthic boundary layer (BBL) extending $200 \mathrm{~m}$ above the sea-floor [9], 78\% $(\mathrm{n}=420)$ of buzzes with measurable altitude occurred within the BBL, indicating benthopelagic foraging. These BBL buzzes were produced at whale-depths from 385 to $1326 \mathrm{~m}$, suggesting that whales were targeting the BBL in these buzzes rather than a specific water depth. This assertion was supported by comparing the variability in whale-altitude and whale-depth for all buzzes with measurable altitude. The interquartile range (IQR) for altitude $(125 \mathrm{~m})<\mathrm{IQR}$ for depth $(197 \mathrm{~m})$, rank-sum $\mathrm{p} \ll 0.001$ on $\mathrm{n}=1000$ bootstrap samples of IQR. Of the BBL buzzes, some $57 \%(\mathrm{n}=240)$ were recorded within $100 \mathrm{~m}$ of the sea-floor while nearly $18 \%(\mathrm{n}=74)$ were performed at more than $150 \mathrm{~m}$ altitude, close to the nominal upper edge of the BBL, making the distinction between bentho- and meso-pelagic foraging somewhat diffuse.

\section{Echo index and foraging activity}

Echoes from organisms in the water column, as detected in tag recordings, were most abundant at depths between 500 and $750 \mathrm{~m}$ both during day and night-time (Fig. 4A; day = 12 tags, 31 dives; night $=3$ tags, 6 dives). Echo counts per depth-bin were lower at night than in day-time, at least at depths between 350 and $900 \mathrm{~m}$ where both day and night data are available (Wilcoxon signedrank, $\mathrm{p} \ll 0.001$ for median equal to $0, \mathrm{n}=13$ depth bins) but echo counts at $<500 \mathrm{~m}$ depth during the day and $<200 \mathrm{~m}$ depth at night may be unreliable because they are based on only a few clicks. The depth distribution of echoes during the day matched fairly closely to two different proxies of foraging effort: the proportion of time spent searching (i.e., making echolocation 
clicks) and the proportion of buzzes (Spearman correlation $\rho=0.49, \mathrm{p}=0.01, \mathrm{n}=20$ for search time and $\rho=0.46, \mathrm{p}=0.02$, $n=20$ for proportion of buzzes) (Fig. $4 A-C$ ). The same proxies of foraging effort were less clearly correlated with echo counts at night-time (Spearman correlation, $\rho=0.42, \mathrm{p}=0.06, \mathrm{n}=15$ for search time and $\rho=0.32, p=0.12, n=15$ for proportion of buzzes) with the highest echo counts being recorded some $150 \mathrm{~m}$ below the depth of greatest foraging effort at night. Thus, foraging during the day concentrates at the depth of higher echo counts and below it, in deeper waters, while most night-time foraging occurred above and below this depth layer. The number of buzzes and the time spent in each depth bin were closely correlated with each other, day and night (Spearman correlation $\rho=0.87, \mathrm{p}<0.001, \mathrm{n}=16$ for night dives and $\rho=0.97, \mathrm{p}<0.001$ $\mathrm{n}=21$ for day dives), resulting in a relatively constant buzz rate (buzzes per minute per depth bin) throughout the water column (Fig. 4D).

\section{Oceanographic and hydroacoustic data}

CTD casts showed a decreasing oxygen concentration with depth reaching a minimum of $0.85 \mathrm{ml} / \mathrm{l}$ at $751 \mathrm{~m}$, roughly one half of the surface concentration. In deeper waters and up to the maximum recording depth $(1000 \mathrm{~m})$, oxygen concentration increased gradually up to $0.94 \mathrm{ml} / \mathrm{l}$. Echosounder data showed a stable DSL between 500-750 m depth both during day and night (Fig. 5B), broadly comparable to the on-animal echo counts (Fig. 4A). At sunset, a portion of the DSL organisms migrated to epipelagic waters to form a second thinner but equally dense layer of organisms, extending from the surface to $200 \mathrm{~m}$ depth. This layer was not detected in the on-animal echo counts because echolocation clicks were rarely produced $<200 \mathrm{~m}$.

\section{Discussion}

Foraging decisions of air-breathing marine predators revolve around locating sufficiently rewarding food patches in a limited dive time, while maximizing the ratio between energy acquired and oxygen spent $[18,28]$. Despite the challenges involved in foraging at depth for marine mammals, more than 20 species have evolved to access mesopelagic depths as top predators in a hostile world of high pressure and darkness. However, little is known about the forces driving niche segregation and habitat selection in deep-diving marine mammals, even though deep waters are one of the largest ecosystems on the planet, and consequently offer a great variety of potential niches and habitats. Foraging resources in the oceans are not homogeneously distributed and deep-diving species must balance the transport costs to reach preferred foraging layers against the caloric value, abundance and the ease with which prey can be caught in these layers [21]. Solutions to this problem vary according to the diving and hunting capabilities of each species [45] but also according to the instantaneous availability of prey, as sensed by the animal [26]. Here we report for the first time the fine-scale meso- and benthopelagic habitat use of a deep diving marine mammal using unique information about the location of biomass in the water column, and the location of the sea-floor, as sensed by the animal itself using echolocation.

\section{Dive cycle \& time budget}

Blainville's beaked whales perform long, deep foraging dives which have been described as extreme for the size of this $4-5 \mathrm{~m}$ whale $[34,44]$. Our results are consistent with previous reports based on a sub-set (28 hours) of the current data-set [34] or obtained using tags without acoustic sensing [44], confirming the extreme diving behavior of this species with dives on average up to
$833 \mathrm{~m}$ and $48 \mathrm{~min}$ duration. Probably as a consequence of performing such protracted dives, which likely involve considerable lactate build up [34], the whales only spend about one third of their time performing foraging dives, of which just one half is spent searching for, and capturing prey. Silent transport between the surface and the foraging layers account for the other half of the duration of each foraging dive.

Compared to sperm whales [33], another echolocating predator foraging at similar depths, Blainville's beaked whales thus spend notably less time per dive searching for prey $(70-90 \%$ of dive time for sperm whales vs. $50 \%$ for beaked whales). This is mainly because beaked whales perform long and low-angle silent ascents from foraging dives [34] while sperm whales ascend vertically to the surface from their foraging depths [33]. Adding the long interforaging-dive intervals, Blainville's beaked whales spend less than a third of the time that sperm whales do searching for prey $(68 \%$ for sperm whales vs. $18 \%$ for beaked whales). This apparent higher foraging efficiency of beaked whales probably reflects differences in foraging requirements between these very different sized animals, as well as the greater diving capacity of sperm whales with a body mass that allows them to extend the foraging time at depth. Beaked whales seem to have adapted to exploit a reliable niche at the cost of performing protracted dive lengths for their size and thus requiring extended resting periods between dives [34]. The relative short foraging periods of the Blainville's beaked whales and the observation that they only initiate searching when already deep in the descent and yet encounter prey suitable for capture within 2 min of the start of echolocation, further supports that these whales are accessing prey in reliable vertical strata, and are likely using cues other than echolocation, such as depth, to guide their biosonar based search for prey. Moreover, these prey resources are sufficiently dense to feed the animals in what is effectively four hours of hunting per day. However reliance on such predictable dense resources may tie Blainville's beaked whales to specific habitats where these are available. In the following we explore what the tag-recorded echolocation data reveal about the location of organisms and the foraging choices of Blainville's beaked whales.

\section{Diel foraging strategy}

Echoes from the sea-floor were detected during most foraging dives and these indicate that Blainville's beaked whales feed both in mesopelagic waters and as close to the sea floor as $5 \mathrm{~m}$. This foraging behavior seems to exploit two stable concentrations of biomass. Most mesopelagic prey capture attempts are performed when the whales are swimming at relatively shallow depths (500 to $850 \mathrm{~m}$ ) broadly coinciding with the lower part of the DSL (Fig. 4A,E). In contrast, whales approach the sea-floor to forage over a wider range of depths, and seem to target exclusively benthopelagic organisms when foraging deeper than $900 \mathrm{~m}$. The steep coastal bathymetry of El Hierro offers a variety of foraging environments on a small spatial scale, with the $1000 \mathrm{~m}$ and $2000 \mathrm{~m}$ isobaths as close as $1.3 \mathrm{~km}$. In this topography, Blainville's beaked whales can switch between meso- and bentho-pelagic foraging in the same dive (e.g., dive 3, Fig. 3A). Foraging choices are probably guided by the type and abundance of prey encountered in each habitat on a dive-by-dive basis, as has been suggested for similar foraging transitions in other marine mammals [22].

The foraging altitude of tagged whales is estimated here using a method that is reliable in steep bathymetry and does not require horizontal localization of animals or accurate bathymetric charts. However, altitude cannot be estimated for about half of the prey capture attempts due to either an unfavourable orientation of the animal or too greater distance to the sea-floor. This may lead to an 
underestimation of the proportion of mesopelagic foraging in our data. But even if all of the buzzes without sea-floor echoes are mesopelagic, at least $43 \%$ of buzzes (420/974) are within the BBL, and many dives contain buzzes in each category, confirming the foraging importance of both domains for Blainville's beaked whales.

Most mesopelagic buzzes during the day occur at and below the peak of the echo-index, indicating that whales are targeting the lower levels of the DSL (Fig. 4E and Fig. 5B), possibly foraging on deeper-living mesopelagic species that are themselves predators of DSL organisms [12]. During the night, whales start searching for food at shallower depths than in daytime (Fig. 5A) and nocturnal foraging peaked at some $150 \mathrm{~m}$ above the main layer of the DSL, suggesting some adaptation of foraging effort to target migrating DSL species (Fig. 4E and Fig. 5B). However, the whales also perform deep dives at night-time to forage on non-migratory or partial migratory organisms of the DSL and on bentho-pelagic prey (Fig. 4E). As a result, the maximum depth and time budget of dives, as well as the overall depth distribution of foraging effort change little from day to night. At first glance, this behavior seems to waste energy in transport without increasing the probability of finding prey, since whales only adapt partially to the depth distribution of the biomass in the water column. However, a closer look at the search behavior of Blainville's beaked whales suggests that they prioritize certain types of prey rather than absolute biomass availability in the water column.

\section{Prey preferences}

Net energy intake for a predator is determined not only by acquisition rate but also by the cost of capturing prey and its caloric content [1]. Caloric contents and locomotory capacities are usually lower in demersal as compared to pelagic species, and tend to decrease with increasing water depths both within the ocean at large and within the DSL [14,46]. The foraging effort of Blainville's beaked whales is concentrated, at least during the day, in the lower levels of the DSL or just below it, coinciding well with the oxygen minimum layer (OML) in the study area (Fig. 5). The OML is a region usually dominated by organisms with low metabolic rates as an adaptation to the low oxygen concentration in the water $[14,47]$ and hence likely with little movement capacity relative to a breath-holding mammalian predator. In contrast, organisms at the medium and upper levels of the DSL have generally higher metabolic rates, representing more active species, especially those that migrate to epipelagic waters at night, and may be better able to perform sustained escape responses to avoid capture $[11,48]$. Migratory organisms tend to be "dormant" during the day but become very active at night, mainly those migrating to epipelagic waters [12]. The potential avoidance capability of prey probably explain why Blainville's beaked whales do not forage shallower than $200 \mathrm{~m}$ depth, despite the nearsurface biomass concentration observed in ship-borne echosounder data at night (Fig. 5). Blainville's beaked whales do not seem to chase their prey over long distances and tend to approach them at slow speeds [32], which supports the idea that they might be targeting prey that are individually low cost to hunt even though this involves an increased cost of transport to reach them at deeper depths. This focus on slow prey is rewarded by the capture of some 30 prey per dive, albeit likely with a low individual caloric content but sufficient to fulfil the energetic requirements of the whales in just four hours of hunting per day.

\section{Search behaviour and habitat use}

We have shown that Blainville's beaked whales switch between meso and bentho-pelagic habitats with foraging decisions being made on a dive-by-dive basis. Whales start echolocating above the DSL and sometimes continue to forage in the mesopelagic domain, probably exploiting more lethargic prey around the OML during the day and non- or partially-migratory DSL organisms at night. In other dives, whales descend below the DSL and approach the sea-floor to search for prey in a down-slope direction. In both cases, the whales start searching for meso- or bentho-pelagic species at relatively shallow depths, and perhaps only commit to deeper bentho-pelagic foraging if shallower prey are not found. The bentho-pelagic habitat in steep slopes around oceanic islands and sea-mounts is often enriched, as these slopes function as ecotones where the pelagic and benthic domains overlap. High concentrations of organisms may be found close to the sea-floor in this habitat as mesopelagic fauna impinge on the slopes, mixing with, and providing additional foraging resources for, demersal species [49]. There are no data on the deep-water productivity of El Hierro but the steep topography of the island [50] suggests that such local-scale enrichment phenomena may occur there. This would explain the presence of a year-round population of Blainville's beaked whales in an area with oligotrophic surface waters [51] that would seem unlikely to sustain a group of large endothermic predators.

The foraging behavior described here may be specific to the resident population of Blainville's beaked whales in El Hierro, adapted to the local topography of the island. However, this species has been reported to distribute over continental slope areas and around oceanic islands in other sub-tropical regions [44,52]. In the three coastal areas of the world where resident populations of any of the 21 species of beaked whales have been found, Blainville's beaked whales are the species that tends to be found in shallower waters nearer the shore [52,53]. The foraging behavior quantified here, and the apparent preference of this species for steep bathymetry, may then help explain its overall distribution. It may be germaine to consider this apparent habitat preference of Blainville's beaked whales when planning activities, such as naval exercises or seismic prospections, that have been related to mass strandings of beaked whales [54,55]. However, the cost and complexity of oceanic studies of beaked whales leads to a strong bias in effort towards coastal populations that are relatively easy to access. Given the large number of beaked whale species and their occurrence in all oceans they almost certainly occupy habitats beyond steep slopes. This is important to keep in mind when extrapolating results from coastal studies.

\section{Conclusions}

We have shown that Blainville's beaked whales spend only four hours per day hunting for food, with such a short foraging time likely resulting from long transport times to foraging depths and long recovery times between deep foraging dives. This necessitates a stable and abundant prey resource that can be located reliably in an extensive 3-dimensional world of darkness. The steep sloping terrains in locations where Blainville's beaked whales are often found may offer access to resources associated with both the DSL and the BBL over a small spatial scale. Echolocating whales can glean both biotic and abiotic cues to aid the efficient location of these resources from biosonar echoes. The enigma of why Blainville's beaked whale abundance is apparently strongly linked to a dense DSL [35], even though they seem to forage outside the DSL, may then be explained by the observation here that whales target prey in the oxygen minimum layer associated with, but deeper than the bulk of the DSL. Thus, by inhabiting steep undersea slopes, Blainville's beaked whales can target a stable and abundant resource of mixed meso and benthopelagic prey using biosonar-derived landmarks. 


\section{Acknowledgments}

We thank L. Martin, M. Bayona, A. Schiavi, C. Reyes, A. Escanez, A. Fais, J. Marrero, M. Tobeña, and many others, including the crew of B/E La Bocaina, for their help in the field, and the people of La Restinga for logistical support. Helpful comments from P. Tyack and one anonymous reviewer improved the manuscript.

\section{References}

1. Pyke GH, Pulliam HR, Charnov EL (1977) Optimal Foraging: A Selective Review of Theory and Tests. Q Rev Biol 52: 137-154.

2. Wilson RP, Pütz K, Bost CA, Culik BM, Bannasch, et al. (1993) Diel dive depth in penguins in relation to diel vertical migration of prey: whose dinner by candlelight?. Mar Ecol Prog Ser 94: 101-104.

3. Kane TC, Poulson TL (1976) Foraging by cave beetles: spatial and temporal heterogeneity of prey. Ecology 57: 793-800.

4. Arditi R, Dacorogna B (1988) Optimal foraging on arbitrary food distributions and the definition of habitat patches. Amer Nat 131: 837-846.

5. Hölldobler B (1980) Canopy Orientation: A New Kind of Orientation in Ants. Science 210: 86-88.

6. Cartwright BA, Collett TS (1982) How honey bees use landmarks to guide their return to a food source. Nature 295: 560-564.

7. Johnson MW (1948) Sound as a tool in marine ecology, from data on biological noises and the deep scattering layer. J Mar Res 7: 443-458.

8. Marshall NB (1965) Systematical and biological studies of the Macrourid fishes (Anacanthini-Teleostii). Deep-Sea Res I 12: 299-3222.

9. Barham E (1966) Deep Scattering Layer migration and composition: observations from a diving saucer. Science 151: 1399-1403.

10. Benoit-Bird KJ, Au WWL, Brainard RE, Lammers MO (2001) Diel horizontal migration of the Hawaiian mesopelagic boundary community observed acoustically. Mar Ecol Prog Ser 217: 1-14

11. Childress JJ (1995) Are there physiological and biochemical adaptations of metabolism in deep-sea animals?. Trends Ecol Evol 10: 30-36.

12. Salvanes AGV, Kristoffersen JB (2001) Mesopelagic fishes. In: Steel J, Thorpe S, Turekian K, eds. Encyclopedia of Ocean Sciences. San Diego: Academic Press. pp 1711-1717.

13. Angel MV, Boxshall GA (1990) Life in the benthic boundary layer: connections to the mid-water and sea floor. Philos Trans R Soc A 33: 15-28.

14. Drazen JC, Seibel BA (2007) Depth-related trends in metabolism of benthic and benthopelagic deep-sea fishes. Limnol Oceanogr 52: 2306.

15. Watanabe Y, Mitani Y, Sato K, Cameron MF, Naito Y (2003) Dive depths of weddell seals in relation to vertical prey distribution as estimated by image data. Mar Ecol Prog Ser 252: 283-288.

16. Benoit-Bird KJ, Wursig B, McFadden CJ (2004) Dusky Dolphin (Lagenorhynchus obscurus) foraging in two different habitats: active acoustic detection of dolphins and their prey. Mar Mam Sci 20: 215-231.

17. Kooyman GL (1989) Diverse divers: physiology and behavior. New York: Springer-Verlag. $216 \mathrm{p}$

18. Butler PJ (2001) Diving beyond the limits. News Physiol Sci 16: 222-227.

19. Aguilar de Soto N, Johnson MP, Madsen PT, Díaz F, Domínguez I, et al. (2008) Cheetahs of the deep sea: deep foraging sprints in short finned pilot whales off Tenerife (Canary Islands). J Anim Ecol 77: 936-947.

20. Thompson D, Duck CD, McConnell BJ, Garrett J (1998) Foraging behaviour and diet of lactating female southern sea lions (Otaria flavescens) in the Falkland Islands. J Zool 246: 135-146.

21. Costa DP (2003) Energetics of a benthic diver: seasonal foraging ecology of the Australian Sea Lion (Neophoca cinerea). Ecol Monograph 73: 27-43.

22. Hindell MA, Slip DJ, Burton HR (1991) The diving behaviour of adult male and female southern elephant seals, Mirounga leonina (Pinnipedia: Phocidae). Aust J Zool 39: 595-619.

23. McConnell B, Chambers C, Fedak M (1992) Foraging ecology of southern elephant seals in relation to the bathymetry and productivity of the Southern Ocean. Antarct Sci 4: 393-398.

24. Waring GT, Hamazaki T, Sheehan D, Wood G, Baker S (2001) Characterization of beaked whale (Ziphiidae) and sperm whale (Physeter macrocephalus) summer habitat in shelf-edge and deeper waters off the northeast US. Mar Mam Sci 17: 703-717.

25. Biuw M, Boehme L, Guinet C, Hindell M, Costa DP, et al. (2007) Variations in behavior and condition of a Southern Ocean top predator in relation to in situ oceanographic conditions. Proc Natl Acad Sci 104(34): 13705-13710.

26. Sims DW, Southall EJ, Humphries NE, Hays GC, Bradshaw CJA, et al. (2008) Scaling laws of marine predator search behaviour. Nature 451: 1098-1102.

27. Davis RW, Fuiman LA, Williams TM, Collier SO, Hagey WP, et al. (1999) Hunting behavior of a marine mammal beneath the antarctic fast Ice. Science 283: 993-996.

28. Wilson RP, Ropert-Coudert Y, Kato A (2002) Rush and grab strategies in foraging marine endotherms: the case for haste in penguins. Anim Behav 63: 85-95.

29. Johnson MP, Aguilar de Soto N, Madsen PT (2009) Studying the behaviour and sensory ecology of marine mammals using acoustic recording tags: a review. Mar Ecol Prog Ser 395: 55-73.

\section{Author Contributions}

Conceived and designed the experiments: NAdS PTM MJ. Performed the experiments: PA NAdS PTM MJ FB. Analyzed the data: PA NAdS PTM MJ. Contributed reagents/materials/analysis tools: PA NAdS PTM MJ FB AB. Wrote the paper: PA NAdS PTM MJ. Performed statistical analyses: PA NAdS MJ.

30. Johnson MP, Tyack PL (2003) A digital acoustic recording tag for measuring the response of wild marine mammals to sound. IEEE J Oceanic Eng 28: 3-12.

31. Johnson MP, Madsen PT, Zimmer WMX, Aguilar de Soto N, Tyack PL (2004) Beaked whales echolocate on prey. Biol Lett 271: 383-386.

32. Madsen PT, Johnson MP, Aguilar de Soto N, Zimmer WMX, Tyack PL (2005) Biosonar performance of foraging beaked whales (Mesoplodon densirostris). J Exp Biol 208: 181-194.

33. Watwood SL, Miller PJO, Johnson MP, Madsen PT, Tyack PL (2006) Deepdiving foaging behavior of sperm whales (Physeter macrocephalus). J Anim Ecol 75: 814-825.

34. Tyack PL, Johnson MP, Aguilar de Soto N, Sturlese A, Madsen PT (2006) Extreme diving of beaked whales. J Exp Biol 209: 4238-4253.

35. Hazen EL, Nowacek DP, St Laurent L, Halpin PN, Moretti DJ (2011) The Relationship among oceanography, prey fields, and beaked whale foraging habitat in the Tongue of the Ocean. PLoS ONE 6(4): e19269. doi:101371/ journalpone0019269.

36. Tyack PL, Zimmer WMX, Moretti D, Southall BL, Claridge DE, et al. (2011) Beaked whales respond to simulated and actual navy sonar. PLoS ONE 6(3): e17009. doi: 101371/journalpone0017009.

37. Davis RW, Fargion GS (1998) Physical habitat of cetaceans along the continental slope in the North-central and Western Gulf of Mexico. Mar Mam Sci 14: 490-507

38. Johnson MP, Madsen PT, Zimmer WMX, Aguilar de Soto N, Tyack PL (2006) Foraging Blainville's beaked whales (Mesoplodon densirostris) produce distinct click types matched to different phases of echolocation. J Exp Biol 209: 5038-5050.

39. Miller PJO, Johnson MP, Tyack PL, Terray EA (2004) Swimming gaits, passive drag and buoyancy of diving sperm whales Physeter macrocephalus. J Exp Biol 207: 1953-1967.

40. Cohen J (1977) Statistical power analysis for the behavioral sciences. New York: Academic Press. 559 p.

41. Jones B, Lavery A, Johnson MP, Madsen PT, Stanton T (2008) Classification of broad-band echoes from foraging beaked whales. J Acoust Soc Am 123: 1753-1762.

42. De Robertis A, Higginbottom I (2007) A post-processing technique to estimate the signal-to-noise ratio and remove echosounder background noise. ICES 64: 1282-1291.

43. Maclennan DN, Fernandes PG, Dalen J (2002) A consistent approach to definitions and symbols in fisheries acoustics. ICES 59: 365-369.

44. Baird R, Webster D, Schorr G, McSweeney D, Barlow J, et al. (2006) Diving behaviour of Cuvier's and Blainville's beaked whales in Hawaï. Can J Zool 84: $1120-1128$.

45. Costa DP, Williams TM (1999) Marine Mammal Energetics. In: Reynolds J, Twiss J, eds. The Biology of Marine Mammals. Washington: The Smithsonian Institution Press. pp 176-217.

46. Seibel BA, Thuesen EV, Childress JJ, Gorodezky L (1997) Decline in pelagic cephalopod metabolism with habitat depth reflects differences in locomotory efficiency. Biol Bull 192: 262-278.

47. Levin LA, Atkinson RJA (2003) Oxygen minimum zone benthos: adaptation and community response to hypoxia. Oceanogr Mar Biol 41: 1-45.

48. Childress JJ, Nygaard MH (1973) The chemical composition of midwater fishes as a function of depth of occurrence off Southern California. Deep-Sea Res I 20: 1093-1109.

49. Mauchline J, Gordon JDM (1991) Oceanic pelagic prey of benthopelagic fish in the benthic boundary layer of a marginal oceanic region. Mar Ecol Prog Ser 74: $109-115$.

50. Gee MJR, Masson DG, Watts AB, Mitchel NC (2001) Landslide and the evolution of El Hierro in the Canary Islands. Mar Geol 177: 271-293.

51. Barton ED, Arístegui J, Tett P, Cantón M, García-Braun J, et al. (1998) The transition zone of the Canary Current upwelling region. Prog Oceanogr 41: 455-504.

52. Claridge DE (2006) Fine-scale distribution and habitat selection of beaked whales. Master of Science in Zoology Thesis University of Aberdeen, Scotland, UK.

53. McSweeney DJ, Baird RW, Mahaffy SD (2007) Site fidelity, associations, and movements of Cuvier's (Ziphius cavirostris) and Blainville's (Mesoplodon densirostris) beaked whales off the island of Hawai'i. Mar Mam Sci 23(3): 666-687.

54. Malakoff D (2002) Seismology - Suit ties whale deaths to research cruise. Science 298: $722-723$.

55. Jepson PD, Arbelo M, Deaville R, Patterson IAP, Castro P, et al. (2003) Gasbubble lesions in stranded cetaceans - Was sonar responsible for a spate of whale deaths after an Atlantic military exercise?. Nature 425: 575-576. 